\title{
Effect of Liquid Hot Water Pretreatment on Selected Properties of Rice Husk and Its Particleboard
}

\author{
Peng Luo,* Chuanmin Yang, Mengyao Li, and Yueqi Wang \\ Rice husk has a water repellent wax layer on its surface and has high $\mathrm{pH}$ \\ and buffering capacity, which inhibit surface adhesion and result in the \\ poor strength and water resistance of rice husk particleboard bonded with \\ water-borne urea formaldehyde (UF) resin. In this work, rice husks were \\ pretreated with liquid hot water at different temperatures $(130,140,150$, \\ and $160{ }^{\circ} \mathrm{C}$ ) and residence times (10 and $20 \mathrm{~min}$ ). Pretreated rice husks \\ were used to produce particleboard with UF resin. The effects of liquid hot \\ water pretreatment temperature and residence time on the wax contents \\ and $\mathrm{pH}$ values were investigated. In addition, the buffering capacities of \\ the rice husks and the mechanical properties and the water resistance of \\ the rice husk particleboards were investigated. The results indicated that \\ liquid hot water pretreatment remarkably reduced the wax contents, $\mathrm{pH}$ \\ values, and buffering capacities of the rice husks. In addition, it improved \\ the mechanical properties and water resistance of the rice husk \\ particleboards. Liquid hot water pretreatment effectively improved \\ bondability between rice husks and water-borne UF resin, and it enhanced \\ the performance of the rice husk particleboard.
}

Keywords: Rice husk; Particleboard; Liquid hot water pretreatment; Urea formaldehyde resin

Contact information: College of Mechanical Engineering, Tianjin University of Commerce, Tianjin 300134, China; *Corresponding author: pengluo@yeah.net

\section{INTRODUCTION}

Each year about 596 million tons of rice are produced globally (Li et al. 2010). Rice husks, the by-product of the rice milling process, which are readily available in large quantities, have not been fully utilized (Ciannamea et al. 2010; Ayrilmis et al. 2012; Kang et al. 2012; Kwon et al. 2013; Tabata et al. 2017). Currently, only a small portion of rice husks are recycled for application in agriculture, livestock, and other sectors; the remaining portion are mainly burnt or used for landfilling (Kwon et al. 2013; Wood et al. 2016), which wastes precious natural resources and causes serious air pollution (Fernandez et al. 2001; Wood et al. 2016). Therefore, the development of new technologies to efficiently utilize rice husk is of great importance (Kang et al. 2012). Rice husk contains $25 \%$ to $35 \%$ cellulose, $8 \%$ to $21 \%$ hemicelluloses, $26 \%$ to $31 \%$ lignin, $15 \%$ to $17 \%$ silica and waxes, and $2 \%$ to $5 \%$ of other soluble substances (Ciannamea et al. 2010). Because the basic chemical components of rice husks are similar to those of wood and they are readily available at relatively low cost, rice husks have the potential to serve as the raw material for particleboard production (Ciannamea et al. 2010; Ayrilmis et al. 2012; Kang et al. 2012). Urea formaldehyde resin, which has a relatively high bonding strength and is easily applicable and inexpensive, is the most used adhesive in wood-based composite panel production (Abdolzadeh et al. 2011). However, UF is not suitable to produce rice husk particleboards due to its weak strength properties, the poor dimensional stability of the resultant panels, and the high resin content requirement (Ciannamea et al. 2010). The 
deficiencies are largely due to the outer surface of rice husk being covered with smooth, water-repellent wax layers, which hinder the further penetration and diffusion of UF (Ciannamea et al. 2010; Ayrilmis et al. 2012; Kwon et al. 2013) and results in poor adhesion between the UF and rice husk particles. In addition, the high $\mathrm{pH}$ and buffering capacity of the crop materials inhibit the curing of $\mathrm{pH}$-sensitive UF resin, which leads to greatly increased resin gel time and weak bonding between crop materials and UF resin (Han et al. 2010; Li et al. 2010). As a result, the rice husk particleboard has poor mechanical properties and water resistance. Removal of the water-repellent wax layers can enhance the adhesion properties of crop materials to adhesives and improve the performance of the particleboard made from the crop materials (Ndazi et al. 2007; Han et al. 2009, 2010; Li et al. 2011). Research works showed that chemical (Han et al. 1999; Li et al.2011), steaming (Han et al. 2009; Li et al. 2011; Baskaran et al. 2013), and steam explosion (Han et al.2010) pretreatment of crop materials are capable of reducing the water-repellent wax content, which enhances the crop materials' wettability and affinity to UF.

Liquid hot water pretreatment, which uses pressure to maintain the water in a liquid state at elevated temperatures for several seconds to several minutes, is applied mainly to pre-hydrolyze and delignify lignocellulosic fiber for bioethanol production (Mosier et al. 2005; Wan and Li 2011; González et al. 2014; Rezania et al. 2020). Water under high pressure and temperature can penetrate the biomass and is able to separate lignocellulosic fiber components while minimizing cellulose hydrolysis (González et al. 2014). Acetic acid and other organic acids generated from autohydrolysis can catalyze further hydrolysis (Wan et al. 2011). Liquid hot water pretreatment, which is an environmentally friendly process, omits the need for neutralization and conditioning chemicals and corrosion resistant materials for the reactor because no chemicals are added (Mosier et al. 2005; Wan and Li 2011; González et al. 2014). The effects of liquid hot water pretreatment on detaching lignocellulosic fiber components strongly depend on pretreatment severity, which is determined by pretreatment temperature and residence time (Mosier et al. 2005; Wan and Li 2011; Rezania et al. 2020). Increasing temperature and/or prolonging residence time may increase the severity of liquid hot water pretreatment. Severe pretreatment conditions result in accretion of organic acids and, as a result, an acidic environment, which promotes the hydration of cellulose and removal of hemicellulose and a portion of lignin; the degradation of fermentable sugars dissolving in the liquid fraction to hydroxymethyl furfural, furfural, formic acid, and levulinic acid is also promoted (Wan and Li 2011). The liquid hot water pretreatment is thought to be capable of destroying the hydrophobic wax layer on rice husk surfaces and improving the bondability between the rice husks and UF resin. There is currently no information regarding the utilization of liquid hot water to pretreat rice husks for rice husk particleboard manufacturing. This work employed a liquid hot water process to pretreat rice husks at different temperatures and residence times. The purpose of crop material pretreatment for particleboard production is to efficiently remove the hydrophobic wax layers covering the surface of crop materials and minimize the degradation of cellulose, hemicellulose, and lignin. To avoid loss of thermal instable hemicelluloses that start to solubilize and hydrolyze at pretreatment temperatures above $150{ }^{\circ} \mathrm{C}$ (Han et al. 2009; Talebnia et al. 2010), less severe pretreatment conditions were employed in this study. The objective of this work was to investigate the effect of pretreatment conditions on the chemical properties of rice husks and rice husk particleboard bonded with UF resin.

Luo et al. (2020). "Pretreated rice husk particleboard," BioResources 15(3), 6714-6723. 


\section{EXPERIMENTAL}

\section{Raw Materials}

The rice husks were acquired from Huiguan Village in the Xiaozhan Township of the Jinnan District (Tianjin, China). Its initial moisture content was approximately 7.16\%. A screen with $0.3-\mathrm{mm}$ mesh was used to manually shed undersized rice husks and dusts.

\section{Liquid Hot Water Pretreatment}

Liquid hot water pretreatment was conducted in a custom-built 15-L batch rotary stainless steel cylindrical autoclave (Model ZQS; Tongda Light Industrial Equipment Corporation, Xianyang, China) with a design pressure of $4 \mathrm{MPa}$ (Fig. 1). The autoclave, connected to a rotary shaft, was equipped with an electrical heater, a motor actuator, a safe valve, a steam releasing valve, a pressure meter ( $0 \mathrm{MPa}$ to $6 \mathrm{MPa})$, and a temperature gauge $\left(0^{\circ} \mathrm{C}\right.$ to $\left.300^{\circ} \mathrm{C}\right)$. The autoclave was loaded with $1.1731 \mathrm{~kg}$ of rice husks (dry weight) and tap water. The solid to water ratio inside the autoclave was $1: 7(\mathrm{~g} / \mathrm{mL}$, dry weight). The autoclave was tightly closed and simultaneously heated and rotated at $1 \mathrm{rpm}$ to ensure appropriate agitation and uniform contact of water with the rice husks. The pretreatment temperatures were $130{ }^{\circ} \mathrm{C}, 140{ }^{\circ} \mathrm{C}, 150{ }^{\circ} \mathrm{C}$, and $160{ }^{\circ} \mathrm{C}$, and the residence times were 10 $\min$ and $20 \mathrm{~min}$. The residence time for each batch was counted when the temperature gauge registered the target temperature. Heating was stopped, and steam was released gradually by opening the steam releasing valve at the end of each treatment. The autoclave was discharged when reaching atmospheric pressure. Both the pretreated rice husks and the liquid became light brown to dark brown in color depending on pretreatment severity (Fig. 2).The pulp was filtered to separate the solid residues (pretreated rice husks) from the liquid fraction. The pretreated rice husks were oven dried at $100 \pm 3{ }^{\circ} \mathrm{C}$ to reach $2 \%$ to $3 \%$ moisture content and placed into plastic bags for future utilization.

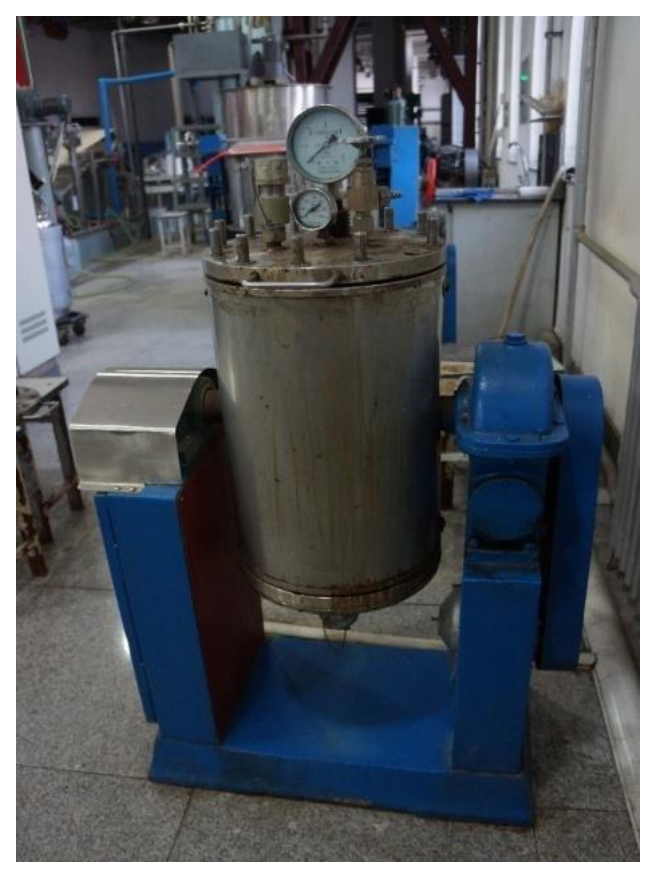

Fig. 1. Image of the autoclave

Luo et al. (2020). "Pretreated rice husk particleboard," BioResources 15(3), 6714-6723. 6716 


\section{Measurement of Chemical Composition, $\mathrm{pH}$, and Buffering Capacities of the Raw and Pretreated Rice Husks}

The ethanol/benzene extractives contents, the $\mathrm{pH}$ values, and the acid and alkali buffering capacities of the raw and pretreated rice husks were measured according to the China National Test Standards of GB/T 2677.6 (1994), GB/T 6043 (2009), and GB/T 17660 (1999), respectively.

\section{Particleboard Preparation}

Commercial UF resin (Zhengzhou Kaibang Chemical Products Co., Ltd., Zhengzhou, China) was used in this study. The UF resin was dispersed with water to reach a solid content of 55\%. The UF resin was sprayed onto rice husks in a blender (Model HWJ 25;Xiaoshan Commercial Equipment Corporation, Zhejiang, China) through a pneumatic atomizing nozzle. The resin application level was $14 \%$ based on the oven-dried weight of the rice husks. To evaluate the water resistance of particleboards made of liquid hot water pretreated rice husks, no water-repelling chemicals were utilized.

The single layer particleboard mats were formed manually using a laboratory mold. The mats were prepressed at $1.5 \mathrm{MPa}$ for $30 \mathrm{~s}$. Then, the mats were hot-pressed in accordance with a three-phase hot press schedule at $130{ }^{\circ} \mathrm{C}$. During the first phase, the mat was pressed at $3.5 \mathrm{MPa}$ for $180 \mathrm{~s}$, and during the second and third phases, the mat was pressed under $2 \mathrm{MPa}$ for 120 sand $1 \mathrm{MPa}$ for $60 \mathrm{~s}$, respectively. The board size was 500 $\mathrm{mm} \times 500 \mathrm{~mm} \times 6 \mathrm{~mm}$ with a target density of $800 \mathrm{~kg} / \mathrm{m}^{3}$. Three panels were made for each condition. The particleboards made from untreated rice husks acted as controls.

\section{Particleboard Evaluation}

After manufacture, the rice husk particleboards were conditioned at $20{ }^{\circ} \mathrm{C}$ and $65 \%$ relative humidity for 2 weeks. Edges of the panels were trimmed to a final dimension of $450 \mathrm{~mm} \times 450 \mathrm{~mm} \times 6 \mathrm{~mm}$. Then, the panels were sawed into test specimens and tested according to the China National Test Standard GB/T 17657 (1999) for density, internal bonding strength (IB), modulus of rupture (MOR), modulus of elasticity (MOE), 24 h water absorption (WA), and thickness swelling (TS). Analysis of variance (ANOVA) and Duncan's mean separation tests were used to statistically analyze the data obtained with SPSS software (SPSS Inc., Version 19, Chicago, IL, USA).

\section{RESULTS AND DISCUSSION}

Table 1. Effect of Liquid Hot Water Pretreatment on Extractives Ethanol/Toluene, $\mathrm{pH}$, and Buffering Capacity of Rice Husks

\begin{tabular}{|c|c|c|c|c|c|}
\hline \multicolumn{2}{|c|}{ Pretreatment Condition } & $\begin{array}{c}\text { Extractives (\%) } \\
\text { (ethanol/benzene) }\end{array}$ & $\begin{array}{c}\mathrm{pH} \\
\text { value }\end{array}$ & $\begin{array}{c}\text { Acid Buffering } \\
\text { Capacity }(\mathrm{mL})\end{array}$ & $\begin{array}{c}\text { Alkali Buffering } \\
\text { Capacity }(\mathrm{mL})\end{array}$ \\
\hline Temp. $\left({ }^{\circ} \mathrm{C}\right)$ & Time (min) & 5.7 & 5.91 & 44.7 & 35.8 \\
\hline \multirow{2}{*}{130} & 10 & 5.4 & 5.70 & 43.8 & 34.7 \\
\cline { 2 - 6 } & 20 & 5.4 & 43.1 & 33.9 \\
\hline \multirow{2}{*}{140} & 10 & 5.0 & 5.47 & 42.3 & 32.6 \\
\cline { 2 - 6 } & 20 & 4.6 & 5.33 & 41.0 & 31.2 \\
\cline { 2 - 6 } & 10 & 4.1 & 4.98 & 40.3 & 30.5 \\
\hline \multirow{2}{*}{160} & 10 & 3.9 & 4.76 & 39.9 & 29.8 \\
\cline { 2 - 6 } & 20 & 3.8 & 4.62 & 39.4 & 28.5 \\
\hline \multicolumn{2}{|c|}{ Untreated } & 3.6 & 4.53 & 48.2 & 37.1 \\
\hline
\end{tabular}




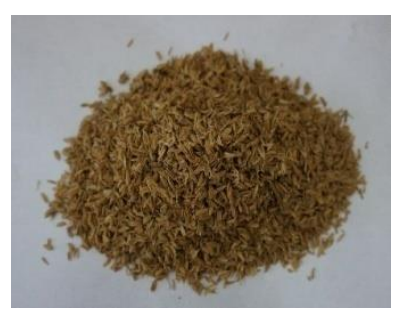

a

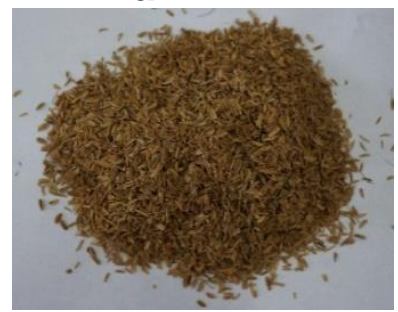

d

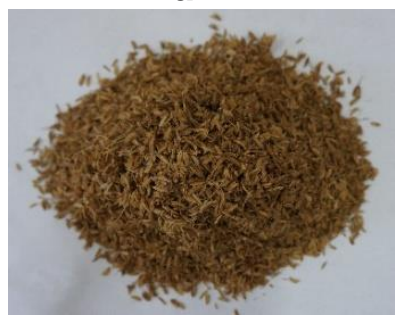

g

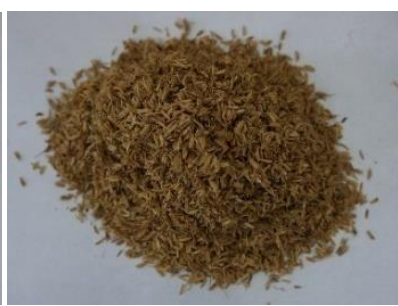

b

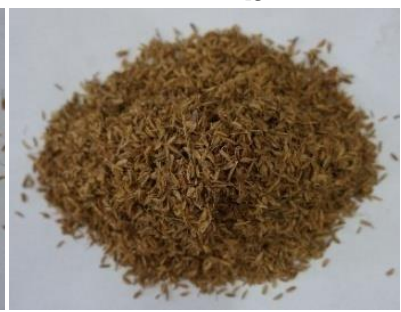

e

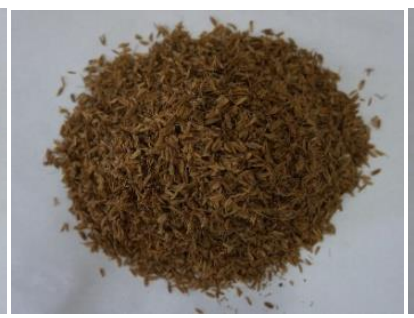

h

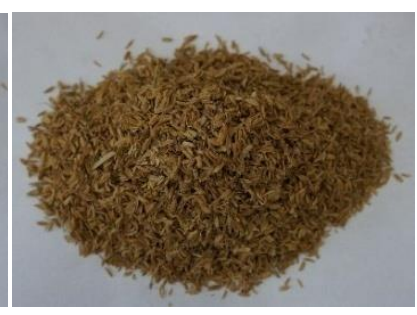

C

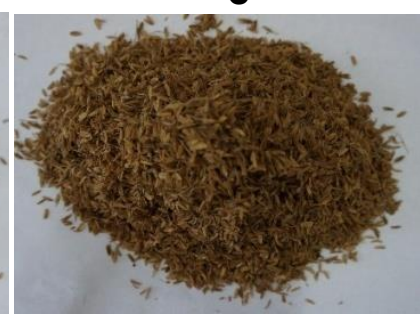

f

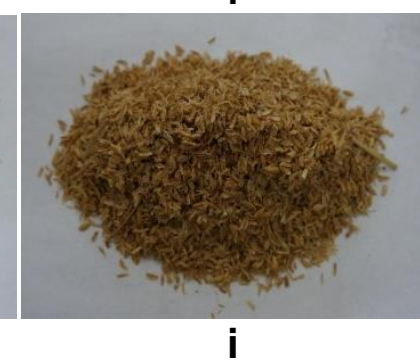

Fig. 2. Images of rice husks before and after liquid hot water pretreatment: (a) pretreated at 130 ${ }^{\circ} \mathrm{C}$ for $10 \mathrm{~min}$; (b) pretreated at $130^{\circ} \mathrm{C}$ for $20 \mathrm{~min}$; (c) pretreated at $140{ }^{\circ} \mathrm{C}$ for $10 \mathrm{~min}$; (d) pretreated at $140{ }^{\circ} \mathrm{C}$ for $20 \mathrm{~min}$; (e) pretreated at $150^{\circ} \mathrm{C}$ for $10 \mathrm{~min}$; (f) pretreated at $150{ }^{\circ} \mathrm{C}$ for 20 min; (g) pretreated at $160^{\circ} \mathrm{C}$ for $10 \mathrm{~min}$; (h) pretreated at $160^{\circ} \mathrm{C}$ for $20 \mathrm{~min}$; (i) Untreated

The $\mathrm{pH}$ values and buffering capacities of acid and alkali from crop materials have been studied in recent years (Zhang et al. 2003; Han et al. 2010). Both the pH values and the acid and alkali buffering capacities were found to be significantly higher than those from softwood (Han et al. 2010). The high $\mathrm{pH}$ and buffer capacities from the crop materials inhibit the curing of $\mathrm{pH}$-sensitive UF resin, which results in greatly prolonged resin gel time and poor bonding strength (Han et al. 2010; Li et al. 2010). Table 1 shows the effects of liquid hot water pretreatment on the $\mathrm{pH}$ values and buffering capacities of acid and alkali of rice husks. As shown in Table 1, the $\mathrm{pH}$ value of untreated rice husks was comparatively high (7.67). The $\mathrm{pH}$ values and buffering capacities of acid and alkali of liquid hot water pretreated rice husks were lowered significantly. The influencing parameters in the liquid hot water pretreatment of lignocellulosic biomass are pretreatment temperature and residence time. The pretreatment temperature had a remarkable impact on the rice husks. As the pretreatment temperature increased, the $\mathrm{pH}$ and buffering capacities of acid and alkali decreased accordingly. Similarly, the residence time had a noticeable effect on the rice husks. As the residence time was prolonged, the $\mathrm{pH}$ and buffering capacities of acid and alkali decreased. As UF resin cures fast under acidic conditions, the increase in acidity of rice husks shortens the curing time of UF resin, which improves the bonding strength of the rice husk particleboard.

Organic solvents such as ethanol/benzene have been found to be capable of extracting the surface wax layers of crop materials (Zhang et al. 2003; Han et al. 2009). Recent studies indicated that a reduction in surface wax content led to a significant 
improvement of the gluing properties of crop materials (Zhang et al. 2003; Han et al. 2010; Li et al. 2010). Table 1 shows that liquid hot water pretreatment effectively reduced the benzene-ethanol extract content. Increasing pretreatment temperature and/or prolonging residence time decreased the benzene-ethanol extract content. These results indicated that the liquid hot water pretreatment efficiently reduced the wax content of rice husks, which eliminated an obstacle to strong adhesion of UF resin on rice husks and enhanced board performance.

Table 2. Properties of Rice Husk Particleboards Under Different Liquid Hot Water Pretreatment Conditions

\begin{tabular}{|c|c|c|c|c|c|}
\hline \multicolumn{2}{|c|}{$\begin{array}{l}\text { Pretreatment } \\
\text { Condition }\end{array}$} & \multirow{2}{*}{$\begin{array}{l}\text { MOR } \\
(\mathrm{MPa})\end{array}$} & \multirow{2}{*}{$\begin{array}{l}\text { MOE } \\
(\mathrm{MPa})\end{array}$} & \multirow{2}{*}{$\begin{array}{c}\text { IB } \\
(\mathrm{MPa})\end{array}$} & \multirow{2}{*}{$\begin{array}{c}24 \mathrm{~h} \text { TS } \\
(\%)\end{array}$} \\
\hline $\begin{array}{l}\text { Temp. } \\
\left({ }^{\circ} \mathrm{C}\right)\end{array}$ & $\begin{array}{l}\text { Time } \\
(\min )\end{array}$ & & & & \\
\hline \multirow{2}{*}{130} & 10 & $11.82 \pm 1.03 b$ & $2037.1 \pm 196.6 b$ & $0.23 \pm 0.018 b$ & $54.95 \pm 3.61 d$ \\
\hline & 20 & $13.09 \pm 1.18 b c$ & $2175.5 \pm 193.2 b$ & $0.27 \pm 0.024 c$ & $50.24 \pm 4.34 \mathrm{~cd}$ \\
\hline \multirow{2}{*}{140} & 10 & $14.65 \pm 1.39 \mathrm{~cd}$ & $2367.1 \pm 196.1 \mathrm{bc}$ & $0.27 \pm 0.022 c$ & $46.18 \pm 3.93 a b c$ \\
\hline & 20 & $15.72 \pm 1.26 \mathrm{de}$ & $2584.6 \pm 221.9 \mathrm{~cd}$ & $0.29 \pm 0.028 \mathrm{~cd}$ & $44.66 \pm 3.38 a b c$ \\
\hline \multirow{2}{*}{150} & 10 & $17.13 \pm 1.57 \mathrm{e}$ & $2758.4 \pm 212.2 \mathrm{c}$ & $0.31 \pm 0.027 \mathrm{~cd}$ & $42.82 \pm 3.73 a b$ \\
\hline & 20 & $15.43 \pm 1.27 d$ & $2536.7 \pm 166.0 \mathrm{~cd}$ & $0.32 \pm 0.029 d$ & $39.46 \pm 2.74 a$ \\
\hline \multirow{2}{*}{160} & 10 & $14.56 \pm 1.32 \mathrm{~cd}$ & $2310.0 \pm 188.6 b c$ & $0.30 \pm 0.027 \mathrm{~cd}$ & $48.92 \pm 4.51 \mathrm{bcc}$ \\
\hline & 20 & $12.89 \pm 1.07 \mathrm{~b}$ & $2119.5 \pm 176.3 b$ & $0.28 \pm 0.027 \mathrm{c}$ & $51.36 \pm 4.27 \mathrm{~cd}$ \\
\hline \multicolumn{2}{|c|}{ Untreated } & $7.47 \pm 0.55 a$ & $1122.5 \pm 94.5 \mathrm{a}$ & $0.07 \pm 0.006 a$ & $66.90 \pm 5.18 \mathrm{e}$ \\
\hline
\end{tabular}

Table 2 demonstrates the effects of the liquid hot water pretreatment condition on the mechanical properties and water resistance of the rice husk particleboard. Clearly, the mechanical properties and water resistance of particleboards made from liquid hot water pretreated rice husks were enhanced remarkably. The liquid hot water pretreatment conditions had a significant influence on the mechanical properties and water resistance of particleboards. The IB values of particleboards made from liquid hot water pretreated rice husks were between 0.23 and $0.32 \mathrm{MPa}$, which indicates a noticeable improvement relative to the control. Appropriately enhancing pretreatment temperature and/or prolonging residence time improved the IB. Pretreatment at $150{ }^{\circ} \mathrm{C} / 20 \mathrm{~min}$ resulted in the highest IB of $0.32 \mathrm{MPa}$, which was approximately 4.57 times that of the control. Further increasing pretreatment temperature and residence time led to a slight decrease in IB, which was still much higher than that of the control. This was attributed mainly to the removal of the waterrepellent wax layer from the surfaces of rice husks and the reduced $\mathrm{pH}$ and reduced acid and alkali buffering capacities that resulted from the liquid hot water pretreatment, which enhanced the wettability and acidity of rice husks. As a result, the bondability of rice husks with the water-borne UF improved, and after hot pressing, the internal bonding of the panels increased. However, as pretreatment temperature and residence time increased further, both the extent of wax layer removal from the outer surfaces of rice husks and the extent of damage to the rice husks can increase. In addition, the $\mathrm{pH}$ and acid and alkali buffering capacities of rice husks decreased as pretreatment severity increased. This may have provoked precuring of the UF resin under acid conditions, which led to the deterioration of bond strength between rice husks and UF resin. Consequently, the IB decreased. Similar observations were also reported in previous studies by Li et al. (2011).

Luo et al. (2020). "Pretreated rice husk particleboard," BioResources 15(3), 6714-6723. 
They stated that the particleboards produced from steam pretreated rice straws exhibited remarkably increased IB.
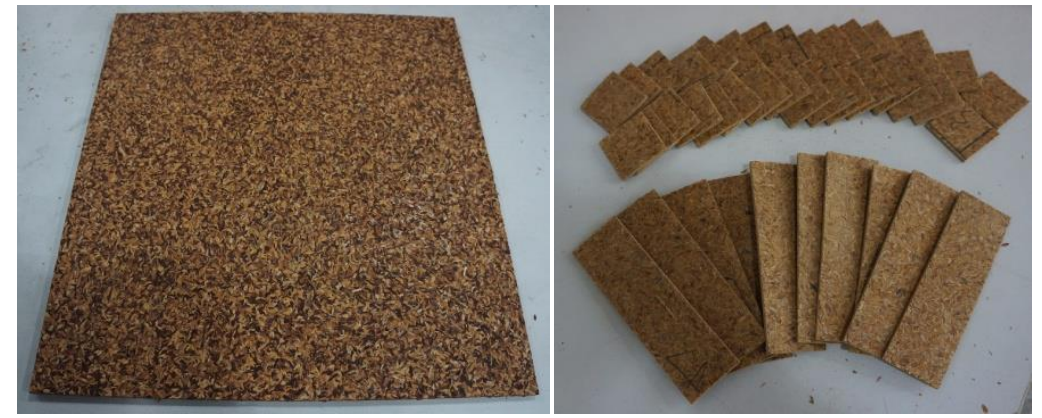

Fig. 3. Image of the rice husk particleboard

The MOR and MOE values of particleboards made from liquid hot water pretreated rice husks were between 11.8 and 17.1 MPa and between 2040 and $2760 \mathrm{MPa}$, respectively. Both MOR and MOE were improved remarkably compared to the control. Appropriately increasing the pretreatment temperature and/or residence time enhanced the MOR and MOE. Under the pretreatment conditions of $150{ }^{\circ} \mathrm{C} / 10 \mathrm{~min}$, the MOR and MOE of the resulting rice husk particleboards reached the peaks of 17.1 and $2760 \mathrm{MPa}$, which were 2.43 times and 2.46 times higher than the control, respectively. This was thought to be due to the removal of the water-repellent wax layers and lowered the $\mathrm{pH}$ and acid and alkali buffering capacities, which increased the bondability of rice husks and the internal bond after hot pressing. As a result, the MOR and MOE were significantly improved. As the pretreatment temperature and/or residence time increased further, the MOR and MOE started decreasing, though they were still much higher than those of the control. This could have been due to damage of the rice husk fibers that resulted from the increase in pretreatment severity. In addition, the increase in the acidity of rice husks with increased pretreatment severity led to precuring of the UF resin, which lowered the bonding strength between rice husks and UF. Consequently, the MOR and MOE decreased. These results were in parallel to the study by Li et al. (2011), who researched the effects of steam pretreatment of rice straw on the performance of the rice straw particleboards.

The effect of the liquid hot water pretreatment on the $24 \mathrm{~h}$ TS is presented in Table 2. Compared to the control, the TS decreased significantly for liquid hot water pretreated particleboards. With increasing pretreatment severity, the TS initially decreased to the minimum of $39.5 \%$ at $150{ }^{\circ} \mathrm{C} / 20 \mathrm{~min}$, which was just $59 \%$ of the control. Further increasing pretreatment severity caused increased TS, which was still much lower than the control. This was mainly due to increased bondability that resulted from pretreatment, which enhanced the internal bond of the panels after hot pressing. Consequently, the quantity of pores inside the panels was reduced, which reduced the access of water to the inside of the panels. Increasing the liquid hot water pretreatment temperature and residence time beyond $150{ }^{\circ} \mathrm{C} / 20$ min enhanced the elimination of hydrophobic wax and lowered $\mathrm{pH}$ and buffering capacities, which caused higher water absorption in rice husks and weaker internal bond of the rice husk particleboards. Consequently, the TS increased. Li et al. (2011) observed similar phenomena when producing particleboards with oxalic acid and steam-pretreated rice straw. 


\section{CONCLUSIONS}

1. Liquid hot water pretreatment was found to be an effective approach to reduce the extractive contents of rice husks. The extractive contents decreased with the increase of pretreatment severity. The reduced extractive contents helped to absorb water-born UF resin and form a strong bond.

2. Liquid hot water pretreatment was an effective method to decrease the $\mathrm{pH}$ values and buffering capacity of rice husks. The $\mathrm{pH}$ values and buffering capacities of acid and alkali decreased with the increase of pretreatment severity. The improved acidity contributed to the fast curing of $\mathrm{pH}$-sensitive UF resin and improve the bondability between rice husk particles and water-born UF resin.

3. The strength properties and water resistance of particleboards made from liquid hot water pretreated rice husks were enhanced significantly. Pretreatment at $150{ }^{\circ} \mathrm{C} / 20 \mathrm{~min}$ resulted in the highest IB of $0.32 \mathrm{MPa}$, which was approximately 4.57 times that of the control. Under the pretreatment conditions of $150{ }^{\circ} \mathrm{C} / 10 \mathrm{~min}$, the MOR and MOE of the resulting rice husk particleboards reached the peaks of 17.1 and $2760 \mathrm{MPa}$, which were 2.43 times and 2.46 times higher than the control, respectively. Pretreatment at $150{ }^{\circ} \mathrm{C} / 20$ min yielded the lowest TS of $39.5 \%$, which was just $59 \%$ of the control. The results suggested that liquid hot water pretreatment was a viable way to improve the bonding strength between rice husks and water-borne UF resin and enhance the overall performance of rice husk particleboard.

\section{ACKNOWLEDGMENTS}

This research was supported by the Key Program for the Natural Science Fund of Tianjin Municipality (Grant No. 15JCZDJC34100) and the Student Research Training Program of Tianjin University of Commerce (Grant Nos.201910069121 and 201910069131).

\section{REFERENCES CITED}

Abdolzadeh, H., Doosthoseini, K., Karimi, A. N., and Enayati, A. A. (2011). "The effect of acetylated particle distribution and type of resin on physical and mechanical properties of poplar particleboard," European Journal of Wood and Wood Products 69(1),3-10. DOI: 10.1007/s00107-009-0390-5

Ayrilmis, N., Kwon, J. H., and Han, T. H. (2012). "Effect of resin type and content on properties of composite particleboard made of a mixture of wood and rice husk," International Journal of Adhesion and Adhesives 38, 79-83. DOI: 10.1016/j.ijadhadh.2012.04.008

Baskaran, M., Hashim, R., Sudesh, K., Sulaiman, O., Hiziroglu, S., Arai, T., and Kosugi, A. (2013). "Influence of steam treatment on the properties of particleboard made from oil palm trunk with addition of polyhydroxyalkanoates," Industrial Crops and Products 51, 334-341. DOI: 10.1016/j.indcrop.2013.09.023 
Ciannamea, E. M., Stefani, P. M., and Ruseckaite, R. A. (2010). "Medium-density particleboards from modified rice husks and soybean protein concentrate-based adhesives," Bioresource Technology 101(2), 818-825.

DOI: 10.1016/j.biortech.2009.08.084

Fernandez, A., Davis, S. B., Wendt, J. O. L., Cenni, R., Young, R. S., and Witten, M. L. (2001). "Public health - Particulate emission from biomass combustion," Nature 409(6823), 998-999. DOI: 10.1038/35059169

GB/T 6043 (2009). "Test methods of $\mathrm{pH}$ value of wood," Standardization Administration of China, Beijing, China.

GB/T 2677.6 (1994). "Fibrous raw material-Determination of solvent extractives," Standardization Administration of China, Beijing, China.

GB/T 17657(1999). "Test methods of evaluating the properties of wood-based panels and surface decorated wood-based panels," Standardization Administration of China, Beijing, China.

GB/T 17660 (1999). "Method for determination of the buffering capacity of wood," Standardization Administration of China, Beijing, China.

González, L. M. L., Reyes, I. P., Dewulf, J., Budde, J., Heiermann, M., and Vervaeren, H. (2014). "Effect of liquid hot water pre-treatment on sugarcane press mud methane yield," Bioresource Technology 169, 284-290. DOI: 10.1016/j.biortech.2014.06.107

Han, G., Cheng, W., Deng, J., Dai, C., Zhang, S., and Wu, Q. (2009). "Effect of pressurized steam treatment on selected properties of wheat straws," Industrial Crops and Products 30(1), 48-53. DOI: 10.1016/j.indcrop.2009.01.004

Han, G., Deng, J., Zhang, S., Bicho, P., and Wu, Q. (2010). "Effect of steam explosion treatment on characteristics of wheat straw," Industrial Crops and Products 31(1), 28-33. DOI: 10.1016/j.indcrop.2009.08.003

Han, G., Umemura, K., Kawai, S., and Kajita, H. (1999). "Improvement mechanism of bondability in UF-bonded reed and wheat straw boards by silane coupling agent and extraction treatments," Journal of Wood Science 45(4), 299-305. DOI: 10.1007/BF00833494

Kang, C. W., Oh, S. W., Lee, T. B., Kang, W., and Matsumura, J. (2012). "Sound absorption capability and mechanical properties of a composite rice hull and sawdust board," Journal of Wood Science 58(3), 273-278. DOI: 10.1007/s 10086-011-1243-5

Kwon, J. H., Ayrilmis, N., and Han, T. H. (2013). "Enhancement of flexural properties and dimensional stability of rice husk particleboard using wood strands in face layers," Composites Part B: Engineering 44(1), 728-732. DOI: 10.1016/j.compositesb.2012.01.045

Li, X., Cai, Z., Winandy, J. E., and Basta, A. H. (2010). "Selected properties of particleboard panels manufactured from rice straws of different geometries," Bioresource Technology 101(12), 4662-4666. DOI:10.1016/j.biortech.2010.01.053

Li, X. J., Cai, Z. Y., Winandy, J. E., and Bastad, A. H. (2011). "Effect of oxalic acid and steam pretreatment on the primary properties of UF-bonded rice straw particleboards," Industrial Crops and Products 33(3), 665-669. DOI: 10.1016/j.indcrop.2011.01.004

Mosier, N., Wyman, C., Dale, B., Elander, R., Lee, Y. Y., Holtzapple, M., and Ladisch, M. (2005). "Features of promising technologies for pretreatment of lignocellulosic biomass," Bioresource Technology 96(6), 673-686. DOI: 10.1016/j.biortech.2004.06.025 
Ndazi, B. S., Karlsson, S., Tesha, J. V., and Nyanumwa, C. W. (2007). "Chemical and physical modifications of rice husks for use as composite panels," Composites Part A: Applied Science and Manufacturing 38(3), 925-935. DOI: 10.1016/j.compositesa.2006.07.004

Rezania, S., Oryani, B., Cho, J., Talaiekhozani, A., Sabbagh, F., Hashemi, B., Rupani, P. F., and Mohammadi, A. A. (2020). "Different pretreatment technologies of lignocellulosic biomass for bioethanol production: An overview," Energy 199, 117457

Tabata, T., Yoshiba, Y., Takashina, T., Hieda, K., and Shimizu, N. (2017). "Bioethanol production from steam-exploded rice husk by recombinant Escherichia coli $\mathrm{KO}_{11}$," World Journal of Microbiology and Biotechnology 33(3), Article number 47. DOI: 10.1007/s11274-017-2221-x

Talebnia, F., Karakashev, D., and Angelidaki, I. (2010). "Production of bioethanol from wheat straw: An overview on pretreatment, hydrolysis and fermentation," Bioresource Technology 101(13), 4744-4753. DOI: 10.1016/j.biortech.2009.11.080

Wan, C., and Li, Y. (2011). "Effect of hot water extraction and liquid hot water pretreatment on the fungal degradation of biomass feedstocks," Bioresource Technology 102(20), 9788-9793. DOI: 10.1016/j.biortech.2011.08.004

Wan, C. X., Zhou, Y. G., and Li, Y. B. (2011). "Liquid hot water and alkaline pretreatment of soybean straw for improving cellulose digestibility," Bioresource Technology 102(10), 6254-6259. DOI: 10.1016/j.biortech.2011.02.075

Wood, I. P., Cao, H.-G., Tran, L., Cook, N., Ryden, P., Wilson, D. R., Moates, G. K., Collins, S. R. A., Elliston, A., and Waldron, K. W. (2016). "Comparison of saccharification and fermentation of steam exploded rice straw and rice husk," Biotechnology for Biofuels 9, Article number 193. DOI: 10.1186/s13068-016-0599-6

Zhang, Y., Lu, X., Pizzi, A., and Delmotte, L. (2003). "Wheat straw particleboard bonding improvements by enzyme pretreatment," Holz als Roh-und Werkstoff 61(1), 49-54. DOI: 10.1007/s00107-002-0349-2

Article submitted: April 28, 2020; Peer review completed: June 21, 2020; Revised version received: July 6, 2020; Accepted: July 7, 2020; Published: July 13, 2020.

DOI: 10.15376/biores.15.3.6714-6723 